\title{
ERRATA-CORRIGE
}

\author{
ERMANNO MARCHIONNA
}

\section{SULLE VARIETA' NORMALI DI COHEN-MACAULAY}

RENDICONTI DEL SEMINARIO MATEMATICO E FISICO DI MILANO VOL. LV (1985) pp. 191-267

$\begin{array}{cccc}\text { Pag. } & \text { Riga } & \text { Errata } & \text { Corrige } \\ 192 & +16 & \text { and we have } & \text { and for } j>1 \text { we have } \\ 228 & +17 & (j \leq d-1) & (j<d-1) \\ 252 & +10 & \Delta \leq \Delta_{l-m} & \Delta_{l} \leq \Delta_{l-m} \\ 260 & +7 & =h_{V}^{j}[n E] & =h_{V_{d}}^{j}[n E]\end{array}$

